\title{
How Do Strigolactones Ameliorate Nutrient Deficiencies in Plants?
}

\author{
Kaori Yoneyama \\ Graduate School of Agriculture, Ehime University, Matsuyama 790-8566, Japan \\ Correspondence: yoneyama.kaori.wx@ehime-u.ac.jp
}

Strigolactones (SLs), a group of plant secondary metabolites, play an important role as a host recognition signal for symbiotic arbuscular mycorrhizal (AM) fungi in the rhizosphere. SLs promote symbioses with other beneficial microbes, including root nodule bacteria. Root parasitic weeds also take advantage of SLs as a clue to locate living host roots. In plants, SLs function as plant hormones regulating various growth and developmental processes including shoot and root architectures. Plants under nutrient deficiencies, especially that of phosphate, promote SL production and exudation to attract symbionts and to optimize shoot and root architecture.

$P$ lants produce various organic chemicals. Primary metabolites including nucleic acids, amino acids, sterols, etc., are present in all plant species and functioning in basic metabolisms. In contrast, some of secondary metabolites-often produced only in very small quantities and rapidly disappear-had been hypothesized to be inessential for plant growth and development. However, highly sensitive analytical methods enabled us to realize the importance of such secondary metabolites as chemical signals with which plants, sessile organisms, can adapt their sensitivity to everchanging and stressful environments.

Plants need inorganic nutrients for their survival but they are very often subjected to nutrient-limited conditions. One of the strategies for overcoming such a difficulty, plants have developed several types of symbiotic relationships with microbes to acquire nutrients. Plants obtain nutrients from microorganisms and, in

turn, supply carbohydrates to them. Plants do not need symbiotic microbes when satisfactory nutrient-rich conditions exist. Therefore, to regulate symbiotic relationships, plants produce and release chemical signals.

The intimate relationship of leguminous plants and nitrogen $(\mathrm{N})$-fixing rhizobacteria is a well-known symbiosis for legumes to obtain $\mathrm{N}$, one of essential macronutrients. As shown in Figure 1, this symbiosis is initiated by the specific chemical signals, flavonoids exuded from roots of N-limited legume plants. Only the compatible rhizobia partners sense the specific flavonoid molecules and induce the expression of nod genes, which stimulate production and exudation of the signals, specific lipochito-oligosaccharides named nodulation (Nod) factors. Then, Nod factors released from the rhizobia induce molecular and physiological changes in the plants (Kouchi et al. 2010; Venkateshwaran et al. 2013), which will be explained later in de-

Editor: Pamela C. Ronald

Additional Perspectives on Engineering Plants for Agriculture available at www.cshperspectives.org

Copyright (C) 2019 Cold Spring Harbor Laboratory Press; all rights reserved; doi: 10.1101/cshperspect.a034686

Cite this article as Cold Spring Harb Perspect Biol 2019;11:a034686 
K. Yoneyama

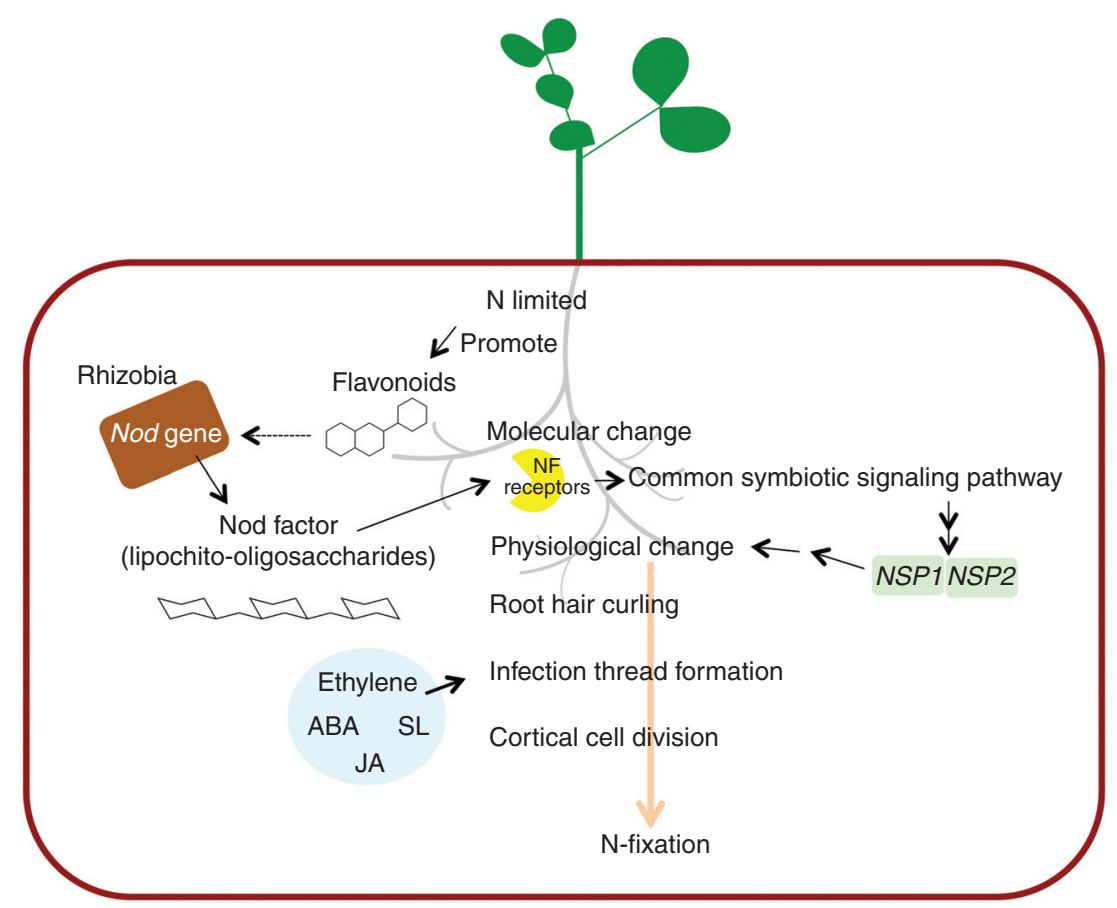

Figure 1. Nodule development in leguminous plants. The nodule development in leguminous plants commences by organic chemical signal flavonoids exuded from roots of plants subjected to nitrogen $(\mathrm{N})$ deficiency. Then, nodulation (Nod) factor signals, lipochitooligosaccharides released from Rhizobia induce molecular and physiological changes of plants to form nodules. Strigolactones (SLs) seem to be related to nodule formation and transcription factors for nodule formation influence SL biosynthesis (see other beneficial functions of SLs in the rhizosphere).

tail. Root nodules fix atmospheric $\mathrm{N}_{2}$ into ammonia, readily available form of $\mathrm{N}$ to plants.

Arbuscular mycorrhizal (AM) fungus is another important symbiotic partner for plants. AM fungi form symbiotic relationships with $>80 \%$ of land plants and they supply nutrients especially phosphate to host plants. Strigolactones (SLs) are key chemical signals for the plant-AM fungi symbiotic relationship, and the objective of this article is to understand how plants use SLs to ameliorate nutrient deficiencies.

The discovery of biological functions of SLs is quite dramatic and SLs are now widely accepted as multifunctional molecules. In this review, a brief history of SL research is introduced to understand various biological functions of SLs. Then, structural diversity, biosynthetic pathway, perception, and signal transduction, regulation of SL production/exudation by nutrient avail- ability, and possible application of SLs for agricultural production is explained.

\section{THE DAWN OF THE STRIGOLACTONE STORY}

The history of SLs began with the isolation of strigol (Fig. 2), the first natural SL, as a germination stimulant of witchweed (Striga lutea), a devastating root parasitic weed (Cook et al. 1966).

Approximately $1 \%$ of angiosperms (3500 to 4000 species) are parasitic plants that depend on their host plants for the supply of part or all of their needs of water, minerals, and photosynthates (Nickrent et al. 1998). Depending on the site of attachment, parasitic plants are divided into two groups: stem and root parasites. The root parasites attach to the roots of host plants and spend most of their lifecycle underground. There are two important root parasitic weeds, 


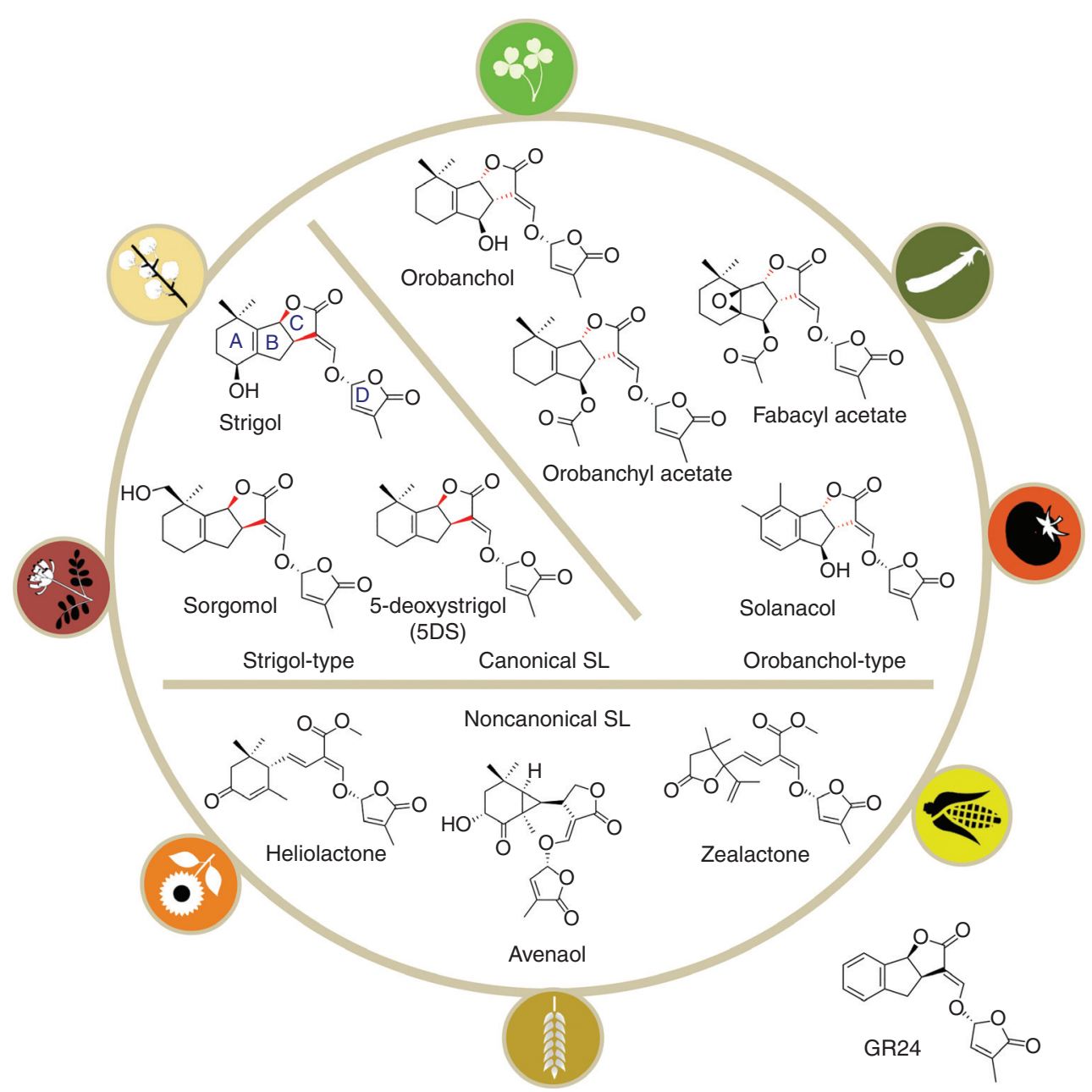

Figure 2. The structures of natural strigolactones (SLs) and synthetic analog GR24.

witchweeds (Striga spp.) and broomrapes (Orobanche and Phelipanche spp.) of Orobanchaceae, causing significant damages to agricultural production all over the world.

Striga spp. are hemiparasites, having functional chloroplasts but obligate parasites, which cannot complete their lifecycle without parasitizing their hosts. They parasitize mainly monocotyledonous crops, for example, maize, sorghum, millet, sugarcane, and upland rice in tropical areas. The United Nations estimates that Striga is the major constraint to crop production in sub-Saharan Africa causing average yield losses of $40 \%$, but total crop failure is common (Ejeta and Gressel 2007).
Orobanche and Phelipanche spp. are holoparasites, lacking chlorophylls and completely depend on host plants. Their host and habitat ranges are quite wide and they parasitize dicotyledonous crops, including legumes, tomato, sunflower, oilseed rape, etc. in temperate areas. The areas threatened by Orobanche and Phelipanche, as estimated in 1991, are 16 million hectares in the Mediterranean and west Asia (Parker 2009).

The problems caused by these root parasitic weeds are not only a significant reduction of crop production but also the limitation of crop transportation. Serious root parasites are classified as quarantine weeds in most countries, and 
thus infested lands must be strictly isolated and the crops harvested there cannot be exported when even a single root parasite is found in the area.

A single root parasite can produce up to half a million tiny seeds that are half the size of Arabidopsis (approximately $0.3 \mathrm{~mm}$ to $0.5 \mathrm{~mm}$ ). They can survive decades in soils, waiting for their preferable crop hosts. The tiny seeds of root parasites with limited food stock will die unless they can parasitize suitable host roots within a few days after germination. An ingenious survival strategy of the root parasites is that the seeds can germinate only when they perceive germination stimulants released from host roots.

Strigol was isolated as a germination stimulant for Striga from root exudates of cotton, a nonhost of Striga. Later, strigol was identified in the root exudates of genuine Striga hosts, sorghum, maize, and common millet (Siame et al. 1993), although recent studies could not confirm the production of strigol by these plant species. Orobanchol (Fig. 2) is the first isolated germination stimulant for Orobanche from root exudates of red clover (Yokota et al. 1998). These strigol-related compounds are collectively called SLs (Butler 1995). The characteristic structures of SLs will be explained in the section on structural diversity.

\section{DISCOVERY OF SLs AS A HOST RECOGNITION SIGNAL FOR AM FUNGI}

Why do plants exude SLs to attract their enemies, root parasitic weeds? Akiyama et al. (2005) first answered this question by showing that SLs function as a host recognition signal for AM fungi. It seems that the root parasites evolved to take advantage of SLs exuded for the symbionts as germination stimulants to recognize the presence of living host roots.

Spores of AM fungi can spontaneously germinate and extend hyphae, which then show extensive hyphal branching only when they perceive hyphal branching factors released from host roots (Giovannetti et al. 1993). 5-Deoxystrigol (5DS) was the first isolated and characterized SL from root exudates of Lotus japonicas, which induces extensive hyphal branching, a critical morphogenetical change in host recognition by AM fungi (Akiyama et al. 2005). These investigators also showed that other natural SLs, sorgolactone and strigol, and the synthetic SL analog GR24 (Fig. 2) induce extensive hyphal branching in germinating spores of the AM fungus Gigaspora margarita at very low concentrations. Besserer et al. (2006) showed that GR24 also stimulates spore germination and hyphal branching of Glomus intraradices and Glomus claroideum through rapid increase of mitochondrial density and respiration.

Experiments with SL-deficient mutants showed that SLs are essential signaling factors for plants to form symbiotic relationships with AM fungi. SL-deficient mutants show significantly reduced AM colonization and exogenously applied GR24 to these mutants partially restores the colonization level (Gomez-Roldan et al. 2008; Yoshida et al. 2012). Petunia hybrida pdr1 (ABC subtype G transporter) mutants defective in SL exudation from their roots show reduced AM colonization (Kretzschmar et al. 2012).

Not only for commencement of AM symbiosis, SLs appear to be necessary for the expansion of root colonization. The time course observation in the SL-deficient rice mutants during the early mycorrhizal stages indicated that most of the colonization process is normal but hyphopodium formation is severely attenuated in the mutants (Kobae et al. 2018). The efficient formation of a hyphopodium leads to the hyphal entry into roots and SLs regulate this process as well.

Not only SLs themselves, the SL receptor is involved in establishing AM symbiosis. The Fbox protein in rice DWARF3 (D3) functions in SL signal transduction (see Fig. 3 ) and $d 3 \mathrm{mu}-$ tant is unable to perceive SLs. Although $d 3 \mathrm{mu}$ tants can produce and exude SLs, they show strong defects in AM fungal colonization (Yoshida et al. 2012). Since expression of AM-inducible marker genes was almost abolished, the molecular responses to AM fungi are dramatically reduced in $d 3$ mutants. A similar phenomenon was observed in garden pea (Pisum sativum L.) (Foo et al. 2013). These results sug- 
A

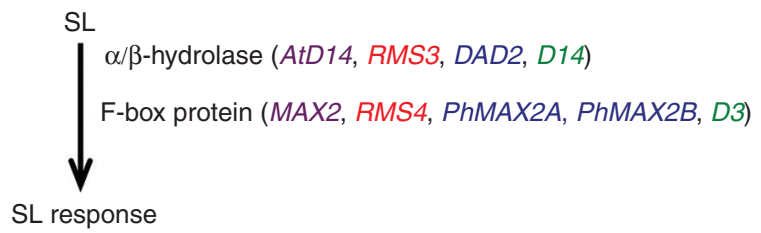

B
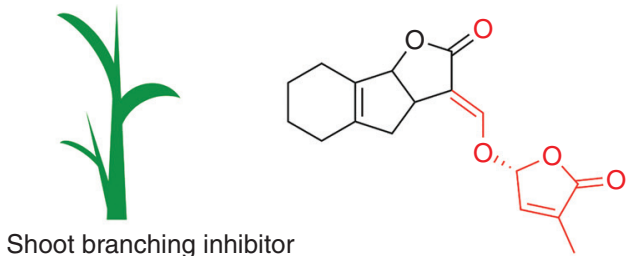

Shoot branching inhibitor
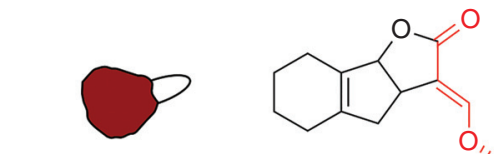

Germination stimulant for root parasitic plant
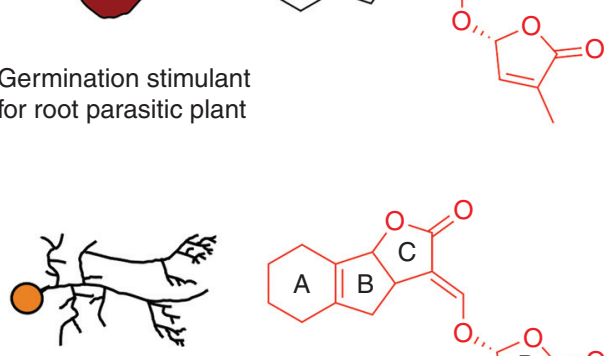

Hyphal branching factor of AM fungi

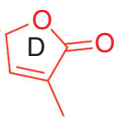

Figure 3. Strigolactone (SL) perception and signaling in shoot branching inhibitory activity $(A)$ and structural requirements of SLs for three biological activities $(B)$. As in $B$, Takahashi and Asami (2018) summarized the structural features of SLs for these activities. The structure essential for the activity is highlighted in red.

gest that SL signal transduction is also essential for AM colonization although the precise mechanism remains elusive.

\section{FURTHER DISCOVERY AS A NEW CLASS OF PLANT HORMONE}

Plants exude SLs not for the root parasites but for AM fungi to promote symbiosis. However, even nonhost plants of AM fungi produce SLs (Yoneyama et al. 2008), suggesting that SLs have some biological functions other than host recognition signal for AM fungi.

Two research groups independently reported at the same time that SLs function as a novel class of plant hormones inhibiting lateral shoot branching by showing that levels of SLs were significantly lower in the mutant plants with excessive shoot branching and application of SLs rescued this phenotype (Gomez-Roldan et al. 2008; Umehara et al. 2008).

Then, new functions of SLs as plant hormones regulating shoot and root architecture have successively been discovered by using the SL-deficient mutants; the phenotypes of SLdeficient mutants can be rescued by application of GR24. The roles of SLs in plant development are summarized in Figure 4.

Plants uptake mineral nutrients from soils by root organs, and thus regulation of root ar- 
A

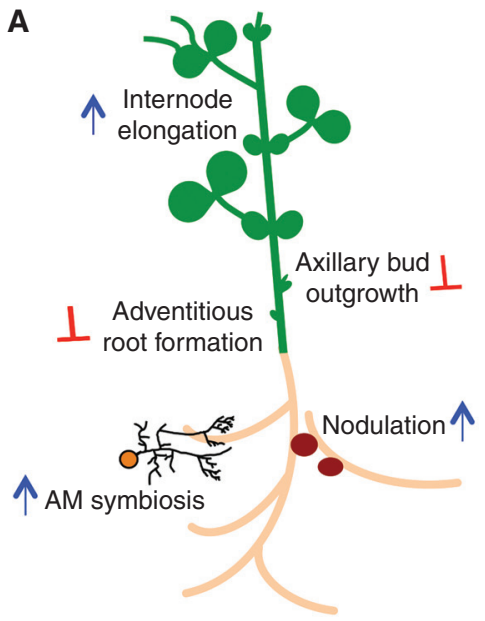

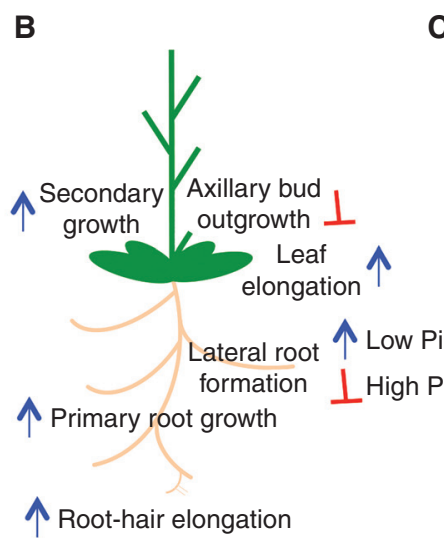

Figure 4. The roles of strigolactones (SLs) in plant development. SLs promote (blue arrows) or inhibit (red bars) various plant growth and developmental processes. These roles have been mainly shown in pea (A), Arabidopsis $(B)$, and rice $(C)$ with SL-deficient mutants. The SL-deficient mutants display a reduced cambium activity (Agusti et al. 2011), delayed leaf senescence (Snowden et al. 2005; Yamada et al. 2014), reduced internode length (de Saint Germain et al. 2013), round leaf shapes (Scaffidi et al. 2013), and enhanced adventitious rooting (Rasmussen et al. 2012). In root growth, SL-deficient mutants show enhanced lateral root formation (Kapulnik et al. 2011), short primary root length (Ruyter-Spira et al. 2011) and short crown root (Arite et al. 2012). These phenotypes are rescued by GR24 treatment.

chitecture via SL production is one of important strategies to improve nutrient acquisition. Auxin, one of plant hormones, has been shown to modulate root architecture and effects of SLs on root growth appear to be dependent on the auxin status of plants (Kapulnik et al. 2011; Koltai 2011; Ruyter-Spira et al. 2011). Therefore, deciphering SL-auxin cross talk is expected to unveil mechanisms underlining the regulation of root development.

\section{OTHER BENEFICIAL FUNCTIONS OF SLS IN THE RHIZOSPHERE}

SLs positively affect not only AM fungi but also rhizobia. Application of GR24 promoted nodule formation in Medicago sativa. Since GR24 did not affect bacterial growth and nod gene expression, this positive effect of SL on Nod would be attributed to the regulation of SL biosynthesis and metabolism or other plant hormone levels in plants (Soto et al. 2010). In fact, SL-deficient pea mutants have less nodules than wild types (WTs) and GR24 elevates nodule number in the mutants (Foo and Davies 2011). McAdam et al. (2017) showed that no major differences in the profile or level of flavonoids in SL-deficient pea mutants and the mutants also display a similar ability to induce root hair curling but significantly fewer infection thread formation as compared with WT plants. These results indicate that SLs are involved in the formation of infection thread (Fig. 1).

Ethylene has a role in infection thread formation (Ferguson et al. 2019). De Cuyper et al. (2015) found that GR24 promotes Nod of Medicago truncatula but not affect ethylene-insensitive mutants, suggesting that ethylene signaling is required for the regulation of Nod by SLs. However, SL-deficient and ethylene-insensitive double mutants display essentially additive phenotypes, suggesting that SLs influence Nod independently of ethylene action (McAdam et al. 2017). Rehman et al. (2018) also showed that SL biosynthetic gene knockdown transgenic hairy roots of soybean (Glycine max) display decreased nodule numbers and expression levels of several genes required for nodule develop- 
ment. In addition, levels of abscisic acid (ABA) and jasmonic acid (JA) increased but that of auxin significantly decreased. These studies suggest that SLs influence Nod via cross talk with other plant hormones (Fig. 1).

Many of the AM symbiosis-impaired mutants identified from legumes are also defective in root Nod and it was shown that AM symbiosis and Nod share the common symbiotic signaling pathway (Parniske 2008). NSP1 (nodulation signaling pathway1) and NSP2 are transcription factors downstream from this signaling pathway, essential for rhizobia Nod factor-induced nodulation (Fig. 1). NPS1 and NPS2 are also indispensable for SL biosynthesis in legumes as well as nonlegume rice; $n s p 1$ and $n s p 2$ mutants show reduced SL levels (Liu et al. 2011). Furthermore, expression of SL biosynthetic genes is elevated by application of rhizobium Nod factors and this elevation is not observed in signaling mutants (van Zeijl et al. 2015). In SL-deficient pea mutants, expression of these signaling genes was down-regulated (McAdam et al. 2017). These results suggest that symbiotic common signals are indispensable for SL biosynthesis and Nod factors may induce SL biosynthesis.

Plants always encounter attacks of pathogenic microbes. SLs have been shown to positively or negatively influence the growth of pathogenic microbes, although there are confusing inconsistencies in effects of GR24 application. Different concentrations of GR24 and different in vitro growth conditions may cause conflicting results. However, experiments with SL biosynthetic knockdown/knockout mutants clearly showed that SLs are related to resistance against pathogenic fungi; SL-deficient tomato (TorresVera et al. 2014) and moss (Physcomitrella patens) (Decker et al. 2017) were more infected by pathogenic fungi as compared with their WTs and the application of GR24 increased the resistance of the mutants and WT to the fungi (Torres-Vera et al. 2014; Decker et al. 2017).

\section{STRUCTURAL DIVERSITY}

To date, more than 30 natural SLs have been identified and can be classified into two structurally distinct groups: canonical and nonca- nonical SLs (Al-Babili and Bouwmeester 2015; Yoneyama et al. 2018b). Canonical SLs contain the ABCD ring system as in the first isolated SL strigol, and noncanonical SLs lack the A, B, or C ring but have the enol ether-D ring moiety (Fig. 2 ), which is essential for biological activities (see Fig. 3). This enol ether-D ring structure is chemically unstable and easily decomposes, which is suitable for AM fungi and root parasitic plants to find their living host roots in the vicinity.

Canonical SLs can be further divided into two groups according to the C-ring stereochemistry, strigol-type and orobanchol-type (Fig. 2), which have a $\beta$ - and $\alpha$-oriented $\mathrm{C}$-ring, respectively (Xie et al. 2013; Al-Babili and Bouwmeester 2015; Yoneyama et al. 2018b). All plant species examined so far have been shown to exude mixtures of several SLs and, in general, plants produce either strigol- or orobancholtype SLs as their major SLs. For example, pea plants produce orobanchol-type SLs including orobanchol, orobanchyl acetate, and fabacyl acetate (Fig. 2). In contrast, major SLs produced and exuded by Chinese milk vetch (Astragalus sinicus) are strigol-type SLs, sorgomol, and 5DS (Fig. 2). So far, orobanchol-type SLs appear to be more widely distributed in the plant kingdom (Yoneyama et al. 2018b), although only limited number of plant species have been examined for characterization of their SLs. The reason why plants produce strigol- and/or orobanchol type SLs remains elusive.

Orobanchol and orobanchyl acetate are widely distributed in Fabaceae plants including red clover, soy, alfalfa, etc. (Yoneyama et al. 2008), and also in the Asteraceae plants including lettuce, marigold, safflower, etc. (Yoneyama et al. 2011). These SLs are also found from rice (Poaceae) but not in Chinese milk vetch (Fabaceae) or cosmos (Asteraceae). Fabacyl acetate was first isolated from root exudates of pea (Xie et al. 2009) and this SL is not detected from the other Fabaceae plants except for fava bean. Solanacol was originally isolated from root exudates of tobacco (Xie et al. 2007) and was detected in other Solanaceae plants including tomato, potato, and eggplant but not in the other plant species. Noncanonical SLs, avenaol (Kim et al. 2014), heliolactone (Ueno et al. 2014), and 
K. Yoneyama

zealactone (Charnikhova et al. 2017; Xie et al. 2017) were isolated from root exudates of oat, sunflower, and maize, respectively (Fig. 2), and these SLs have not been detected from the other plants examined so far. Therefore, some SLs are specific to particular plant species and plant families. It is intriguing to understand why plants produce and exude mixture of SLs.

Interestingly, SL compositions sometimes differ among cultivars within the same plant species (Yoneyama et al. 2011). In sorghum, large differences in SL compositions have been observed between cultivars resistant and susceptible to the root parasite Striga hermonthica. Striga resistant cultivars exude orobanchol as a major SL, whereas 5DS is the major SL produced by susceptible cultivars (Mohemed et al. 2016). It was also shown by these same investigators that 5DS is highly active Striga germination stimulant, whereas orobanchol is a very weak one. These results suggest that qualitative differences of SLs determine the susceptibility/resistance to the root parasitic weed. In contrast, although the distinctive difference in SL composition was observed between Striga resistant/susceptible maize cultivars, the levels of AM colonization and the community compositions were not different between the cultivars (Yoneyama et al. 2015). The same phenomenon was observed in sorghum cultivars (Gobena et al. 2017). These results imply that the traits involved in Strigaresistance would not necessarily be accompanied by the reduction in compatibility to AM fungi.

\section{SL BIOSYNTHETIC PATHWAY}

The genes of SL biosynthesis and perception/ signaling were named MAX (MORE AXILLARY GROWTH) in Arabidopsis, $D$ (DWARF) in rice, RMS (RAMOSUS) in pea, and DAD (DECREASED APICAL DOMINANCE) in petunia (Dun et al. 2009; Beveridge and Kyozuka 2010; Al-Babili and Bouwmeester 2015).

As shown in Figure 5, the core pathway of SL biosynthesis starts from all-trans- $\beta$-carotene, which is converted into 9 -cis- $\beta$-carotene by an isomerase D27. 9-cis- $\beta$-carotene is converted by sequential reactions of carotenoid cleavage dioxygenase7 (CCD7) and CCD8 into carlactone
(CL), the first SL-backbone molecule (Alder et al. 2012).

D27 was first cloned from rice as a geneencoding an iron-binding protein with unknown catalytic function (Lin et al. 2009) and AtD27 was identified as an ortholog of rice D27 in Arabidopsis (Waters et al. 2012a), which functions as an isomerase. Shoot branching phenotype of $d 27$ mutants in rice and Arabidopsis is milder than the other SL-related mutants (Lin et al. 2009; Waters et al. 2012a). Other D27-like proteins exist in rice, Arabidopsis, and the other plant species (Waters et al. 2012a; Jia et al. 2018). These results suggest that D27 homologs function in the formation of 9 -cis- $\beta$-carotene or other precursors for the later steps of SL biosynthesis.

CCD7 genes identified are single copy, whereas rice, maize, and sorghum have four, two, and six copies of CCD8, respectively (Vallabhaneni et al. 2010). CCD8 copies can be divided into two groups $C C D 8 a$ and $C C D 8 b$ by phylogenetic tree analysis. The conversion of 9 -cis- $\beta-10$-carotenal into CL is catalyzed by $C C D 8 a$. The function of $C C D 8 b$ remains elusive and Arabidopsis does not have CCD8b (Wang and Bouwmeester 2018).

CL was originally discovered in an Escherichia coli in vitro system (Alder et al. 2012) and later shown to be an endogenous precursor of canonical and noncanonical SLs in Arabidopsis and rice (Seto et al. 2014). In Arabidopsis, max 1 mutants with highly shoot branching phenotype significantly accumulate CL, indicating CL is just an intermediate of SL biosynthesis but not a true shoot branching inhibitor (Abe et al. 2014; Seto et al. 2014). Moss CCD7 and CCD8 in vitro convert 9-cis- $\beta$-carotene into $C L$, suggesting that this early stage of SL biosynthesis is evolutionarily conserved between lower and higher plants (Decker et al. 2017).

In Arabidopsis, cytochrome P450 monooxygenase MAX1 (CYP711A in the P450 family) catalyzes the oxidation of the $\mathrm{C}-19$ methyl group of CL to produce carlactonoic acid (CLA), and CLA is converted by unknown methyl transferase into methyl carlactonoic acid (MeCLA) (Abe et al. 2014). Among CL, CLA, and MeCLA, only MeCLA can interact with the SL receptor 

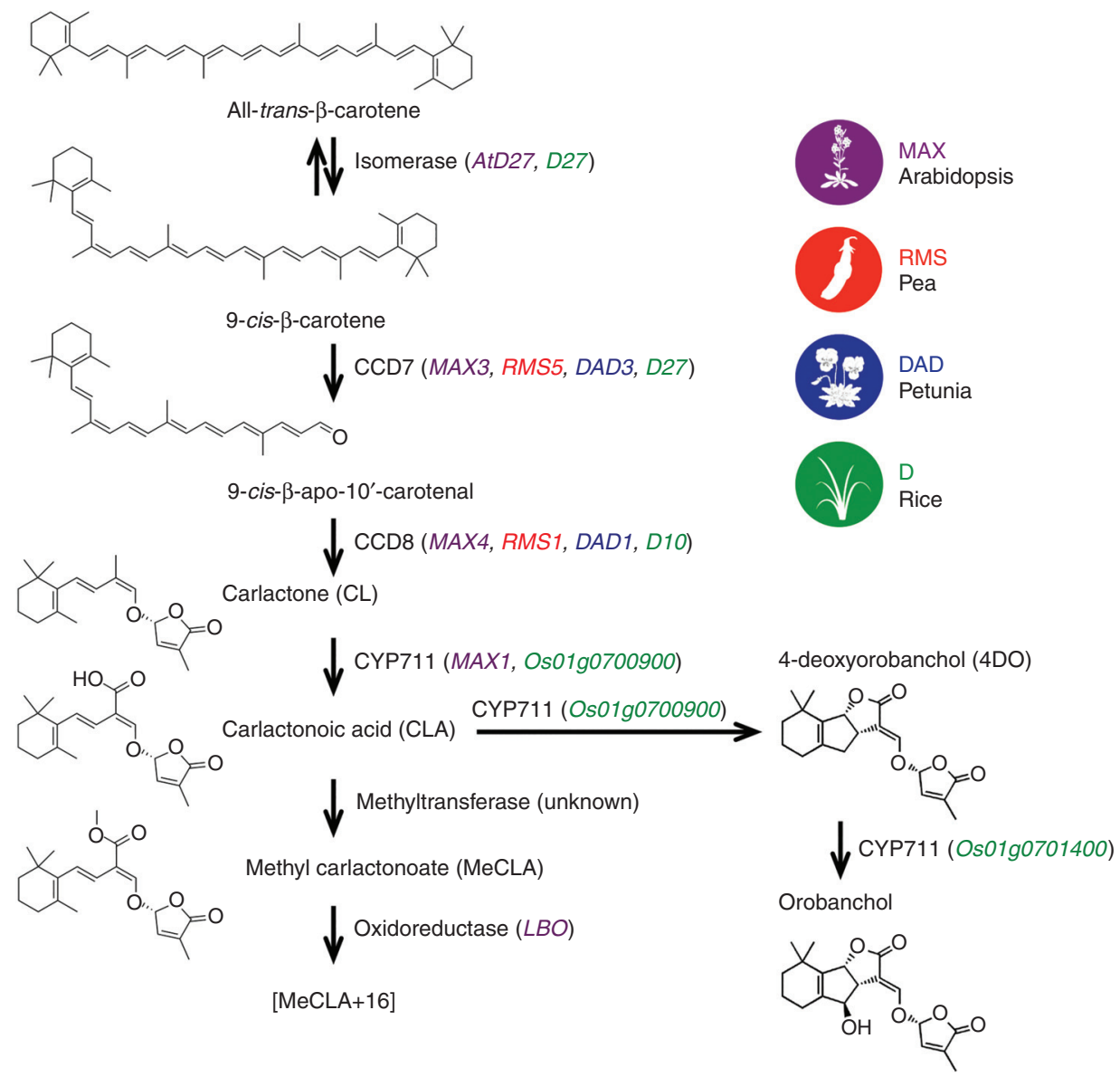

Figure 5. The biosynthetic pathway of strigolactones (SLs). Genes and their encoded proteins are shown.

D14, suggesting that MeCLA may be a true shoot branching inhibitor. However, LATERAL BRANCHING OXIDOREDUCTASE (LBO), a gene encoding an oxidoreductase-like enzyme of the 2-oxoglutarate and Fe(II)-dependent dioxygenase superfamily was identified by using reverse genetics; $L B O$ was found to be coexpressed with other SL biosynthetic genes and lbo mutants display enhanced shoot branching (Brewer et al. 2016). LBO was found to convert MeCLA into a compound with (MeCLA + 16) Da whose structure remains elusive as a result of its instability (Brewer et al. 2016).

Among four MAX1 homologs, one MAX1 homolog CYP711A2/Os900 catalyzes the B-C ring closure and stereoselective conversion of CL into 4DO, a major SL in rice (Zhang et al.
2014). Subsequently, another MAX1 homolog, CYP711A3/Os1400 catalyzes the hydroxylation of 4DO into orobanchol (Zhang et al. 2014). Both of these rice MAX1s also convert CL to CLA as does Arabidopsis MAX1 (Yoneyama et al. 2018a).

The later steps of SL biosynthetic pathway remain elusive. MAX1 and LBO appear to be key enzymes for the production of structurally diverse SLs. The biochemical functions of MAX1 and LBO may vary with plant species.

\section{SL PERCEPTION AND SIGNALING}

SLs function for at least three classes of organisms, plants, root parasitic plants, and AM fungi, and perception of SLs and signaling pathway 
K. Yoneyama

have been extensively studied in plants and root parasitic plants.

The SL receptor in plants, D14 in rice (Arite et al. 2009), Atd14 in Arabidopsis (Waters et al. 2012b), DAD2 in petunia (Hamiaux et al. 2012), and RMS3 in pea (de Saint Germain et al. 2016) were characterized (Fig. 3A). The receptor D14, having a strictly conserved Ser-His-Asp catalytic triad, belongs to $\alpha / \beta$-hydrolase superfamily and unusually functions not only as a receptor but also as a hydrolysis enzyme (Hamiaux et al. 2012; Nakamura et al. 2013). Yao et al. (2016) and de Saint Germain et al. (2016) suggested by crystallographic studies that D14 cleaves SLs into the $\mathrm{ABC}$-ring and $\mathrm{D}$-ring moieties, and the D-ring covalently binds to the receptor pocket and triggers the association of the receptor with the F-box protein. In contrast to this mechanism, Seto et al. (2019) recently suggested that intact SL molecules trigger the D14 active signaling state and D14 deactivates bioactive SLs by the hydrolytic degradation after signal transmission.

SL signal transduction proceeds in a mechanism similar to that occurs in other plant hormones; SL responses require the F-box protein MAX2 whose gene was first cloned in Arabidopsis (Stirnberg et al. 2002; see Fig. 3A for MAX2 orthologs in other species). Intriguingly, MAX2 also mediates responses to karrikins (KARs), a family of butenolide compounds found in smoke, which induce seed germination after fire (Flematti et al. 2004; Nelson et al. 2011). Furthermore, KAR responses in Arabidopsis require KARRIKIN INSENSITIVE 2 (KAI2), a paralog of D14. In the root parasitic weed Striga, KAI2 and KAI2 paralogs function as the SL receptors (Conn et al. 2015; Toh et al. 2015; Tsuchiya et al. 2015).

The SL receptor in AM fungi is not known. AM fungus Rhizophagus irregularis appears to contain no clear homologs of either D14 or MAX2 (Tisserant et al. 2013; Waters et al. 2017), suggesting that mycorrhizal SL receptor is different from that in plants. Although all canonical SLs except 5DS have been isolated as germination stimulants for root parasites and are active as hyphal branching factors for AM fungi (Akiyama et al. 2010), structural require- ments of SLs appear to be similar but not identical in each biological activity (Fig. 3B). GR5 lacking the A- and B-ring of GR24 is almost inactive in hyphal branching of G. margarita (Akiyama et al. 2010), whereas GR5 is as active as GR24 in shoot branching inhibition of pea (Boyer et al. 2012). In hyphal branching, noncanonical SLs are generally less active than canonical SLs except for CLA (Mori et al. 2016). These results suggest that the $\mathrm{ABC}$-ring moiety is important for hyphal branching activity of SLs in AM fungi (Fig. 3B).

Orobanchol and strigol are canonical SLs with a hydroxyl group at different positions and opposite C-ring stereochemistry (Fig. 2). In the hyphal branching of G. margarita, orobanchol is 100-fold more active than strigol (Akiyama et al. 2010). Further studies are needed to clarify the effects of SLs on various species of AM fungi and on their colonization of plant roots in the fields.

\section{REGULATION OF SL PRODUCTION AND EXUDATION BY NUTRIENT AVAILABILITY}

$\mathrm{N}$ deficiency and especially phosphorus (P) deficiency significantly promote SL production/ exudation. Plants under nutrient deficiencies enhance SL production and exudation to promote mycorrhizal symbiosis for better nutrient acquisition and suppress lateral shoot branching to save the growth energy.

As described earlier, orobanchol was isolated as a germination stimulant of Orobanche minor, clover broomrape, from root exudates of red clover (Yokota et al. 1998). It took 8 years to isolate pure orobanchol in amounts enough for structural determination. These investigators grew many red clover seedlings to collect root exudates containing germination stimulants. Red clover plants grew well under nutrient-rich conditions; however, germination stimulant activity of root exudates significantly reduced (Yoneyama et al. 2001). Then, it was found that deficiency of $\mathrm{P}$ but not $\mathrm{N}$, potassium, calcium, or magnesium significantly promotes orobanchol exudation in red clover (Yoneyama et al. 2007b). Now it is widely accepted that $\mathrm{P}$ deficiency enhances SL production and exuda- 
tion. In rice, a negative correlation between SL levels in roots and the numbers of tillers was observed (Umehara et al. 2010).

In the case of sorghum, $\mathrm{N}$ deficiency as well as $\mathrm{P}$ deficiency remarkably promotes SL production and exudation (Yoneyama et al. 2007a). Such a difference in response of SL production and exudation to nutrient deficiencies between red clover and sorghum is owing to their different reliability on AM fungi for $\mathrm{N}$ acquisition. Red clover is a leguminous plant and can obtain $\mathrm{N}$ from symbiosis with root nodule bacteria. In contrast, nonlegume sorghum depends on AM fungi for the supply of both $\mathrm{N}$ and $\mathrm{P}$, although contribution of AM fungi is significantly larger in P supply than in that of $\mathrm{N}$ (Govindarajulu et al. 2005). As expected, a legume alfalfa (M. sativa) enhanced SL production and exudation only under $\mathrm{P}$ deficiency, whereas nonlegume lettuce (Lactuca sativa) and marigold (Tagetes patula) responded to both $\mathrm{N}$ and $\mathrm{P}$ deficiencies. However, unexpectedly, a legume Chinese milk vetch (A. sinicus) enhanced SL production and exudation under $\mathrm{N}$ deficiency as well as $\mathrm{P}$ deficiency and the nonlegume tomato (Solanum lycopersicum) did not respond to $\mathrm{N}$ deficiency (Fig. 6; Yoneyama et al. 2012). From these results, responses in SL production and exudation to nutrient availability are not directly related to the plant's ability to form symbiotic relationships with rhizobia.
Although canonical SLs were detected from root exudates of a legume white lupin (Lupinus albus), a host of rhizobia but nonhost of AM fungi, neither $\mathrm{P}$ nor $\mathrm{N}$ deficiency increased SL exudation in this plant (Yoneyama et al. 2008). It is reasonable that nonhost plants of AM fungi do not promote SL exudation under nutrient deficiency. However, even nonhost plants would enhance SL production to regulate shoot and root architecture under nutrient deficiency. Kohlen et al. (2011) showed in Arabidopsis, a nonhost of AM fungi, that $\mathrm{P}$ deficiency promoted SL production and suppressed shoot branching.

Expression of SL biosynthetic genes, D27, D10, D17, and CYP711 is up-regulated in rice roots by $\mathrm{P}$ deficiency (Umehara et al. 2010). Sulfur (S) deficiency also promotes SL production and exudation and only D27 is strongly expressed (Shindo et al. 2018). S is also supplied by AM fungi (Smith and Read 2008). These results suggest that D27 may play an important role in effective $S$ acquisition via AM symbiosis (Shindo et al. 2018). AM fungi supply other mineral nutrients including zinc, copper, etc. So far, there are no reports if these mineral deficiencies affect SL production and exudation. Different plant species may respond to different nutrient deficiencies. The detailed mechanisms of regulation of SL production/exudation by nutrients need to be elucidated in the future.

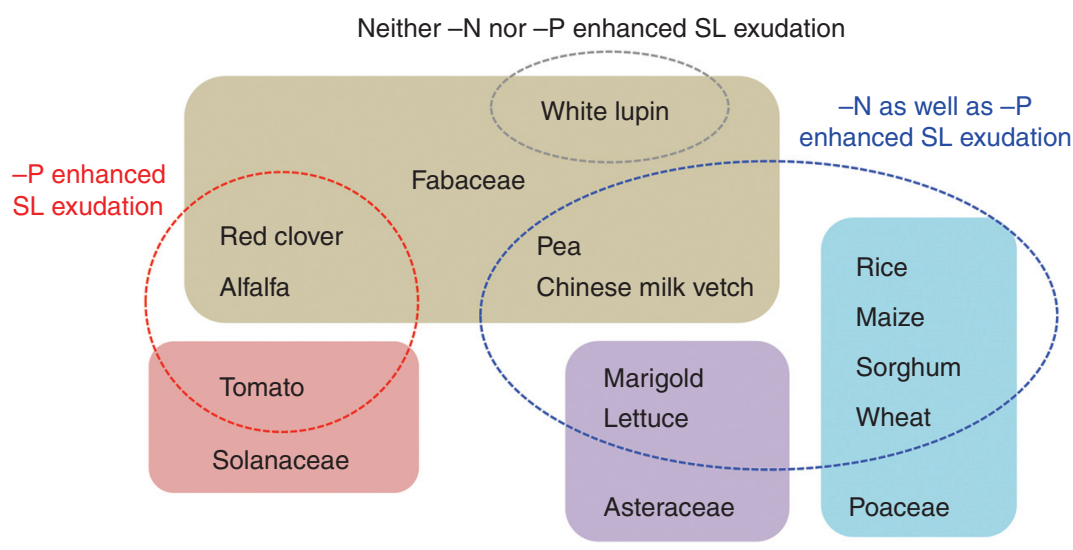

Figure 6. Summary of strigolactone (SL) responses to nutrient availabilities. Plants are classified into three groups according to their responses in SL exudation to nutrient deficiencies. 
K. Yoneyama

\section{APPLICATION OF SLs TO AGRICULTURAL PRODUCTION}

Recent reports shed a new light on the management of serious problems caused by root parasitic weeds. Gobena et al. (2017) identified the gene responsible for regulating Striga resistance in sorghum, LOW GERMINATION STIMULANT1 (LGS1). Sorghum plants with loss-offunction mutations in LGS1 produce and exude orobanchol instead of 5DS, a major SL of Striga susceptible WT sorghum varieties. The Striga resistant sorghum genotype SRN39 carrying the mutated LGS1 allele (lgs1-1) supports fewer parasites in field plots, whereas LGS1 WT sorghum is heavily infested. LGS1 seems to be a good marker for breeding and genome editing for other crops to obtain Striga resistance.

Suicidal germination, induction of germination of root parasites in the absence of host plants, is one of the effective methods used to suppress the root parasitic weeds. Uraguchi et al. (2018) developed a femtomolar-range suicidal germination stimulant for S. hermonthica, sphynolactone-7 (SPL7), which is inactive in other SL-related biological functions including hyphal branching of AM fungi or inhibition of shoot branching. Soil treatment with SPL7 at >100 pM before maize planting could reduce emergence of Striga and protected the crop from senescence caused by parasitism. This compound would be a good lead for the development of suicidal germination inducers, which effectively reduce seed bank of Striga and other root parasitic weeds but not affect shoot and root architectures or AM fungi colonization.

SLs may be used to promote root colonization by symbionts including AM fungi. For this, it is better to develop SL agonists active only in hyphal branching of AM fungi. On the other hand, SL agonists active only in the regulation of shoot architecture may be used to control number of flowers and fruits.

\section{CONCLUDING REMARKS}

To gain further knowledge on the topics discussed in this review, please refer to excellent reviews on biology and management of root par- asites (Joel et al. 2007), whole SL story (Xie et al. 2010), shoot branching functions of SL (Dun et al. 2009; Beveridge and Kyozuka 2010), SL biosynthesis (Al-Babili and Bouwmeester 2015; Jia et al. 2018), and SL perception and signaling (Waters et al. 2017; Takahashi and Asami 2018; Tsuchiya 2018). Many important questions on biosynthesis, functions, and biological roles of SLs remain to be solved: Which are key genes or enzymes determining diverse structures of SLs? Why do plants produce and exude mixture of SLs? These mysteries of SLs keep attracting us. Furthermore, are root parasitic weeds and AM fungi rivals or friends under nutrient-deficient conditions? Are there any possibilities that root parasitic weeds help their host plants, AM fungi, or the other organisms? Further studies from different scientific approaches, for example, studies with various SL modulators (inhibitors of perception, biosynthesis, and function of SLs, SL agonists, and SL antagonists) (Yoneyama et al. 2019) may open the way to answer these questions.

\section{ACKNOWLEDGMENTS}

I thank Dr. Koichi Yoneyama (Utsunomiya University) for critical reading of the manuscript. This work was supported by the Japan Society for the Promotion of Science (KAKENHI 15J40043 and 16K18560) and the Japan Science and Technology Agency, Precursory Research for Embryonic Science and Technology (PRESTO).

\section{REFERENCES}

\footnotetext{
Abe S, Sado A, Tanaka K, Kisugi T, Asami K, Ota S, Kim HI, Yoneyama K, Xie X, Ohnishi T, et al. 2014. Carlactone is converted to carlactonoic acid by MAX1 in Arabidopsis and its methyl ester can directly interact with AtD14 in vitro. Proc Natl Acad Sci 111: 18084-18089. doi:10.1073/ pnas. 1410801111

Agusti J, Herold S, Schwarz M, Sanchez P, Ljung K, Dun EA Brewer PB, Beveridge CA, Sieberer T, Sehr EM, et al. 2011. Strigolactone signaling is required for auxin-dependent stimulation of secondary growth in plants. Proc Natl Acad Sci 108: 20242-20247.

Akiyama K, Matsuzaki K, Hayashi H. 2005. Plant sesquiterpenes induce hyphal branching in arbuscular mycorrhi zal fungi. Nature 435: 824-827. doi:10.1038/nature03608
} 
Akiyama K, Ogasawara S, Ito S, Hayashi H. 2010. Structural requirements of strigolactones for hyphal branching in AM fungi. Plant Cell Physiol 51: 1104-1117. doi:10 $.1093 / \mathrm{pcp} / \mathrm{pcq} 058$

Al-Babili S, Bouwmeester HJ. 2015. Strigolactones, a novel carotenoid-derived plant hormone. Annu Rev Plant Biol 66: 161-186. doi:10.1146/annurev-arplant-043014114759

Alder A, Jamil M, Marzorati M, Bruno M, Vermathen M, Bigler P, Ghisla S, Bouwmeester H, Beyer P, Al-Babili S 2012. The path from $\beta$-carotene to carlactone, a strigolactone-like plant hormone. Science 335: 1348-1351. doi:10 $.1126 /$ science. 1218094

Arite T, Umehara M, Ishikawa S, Hanada A, Maekawa M, Yamaguchi S, Kyozuka J. 2009. d14, a strigolactone-insensitive mutant of rice, shows an accelerated outgrowth of tillers. Plant Cell Physiol 50: 1416-1424. doi:10.1093/ pcp/pcp091

Arite T, Kameoka H, Kyozuka J. 2012. Strigolactone positively controls crown root elongation in rice. J Plant Growth Regul 31: 165-172.

Besserer A, Puech-Pagès V, Kiefer P, Gomez-Roldan V, Jauneau A, Roy S, Portais JC, Roux C, Bécard G, Séjalon-Delmas N. 2006. Strigolactones stimulate arbuscular mycorrhizal fungi by activating mitochondria. PLoS Biol 4: e226. doi:10.1371/journal.pbio.0040226

Beveridge CA, Kyozuka J. 2010. New genes in the strigolactone-related shoot branching pathway. Curr Opin Plant Biol 13: 34-39. doi:10.1016/j.pbi.2009.10.003

Boyer FD, de Saint Germain A, Pillot JP, Pouvreau JB, Chen VX, Ramos S, Stévenin A, Simier P, Delavault P, Beau JM, et al. 2012. Structure-activity relationship studies of strigolactone-related molecules for branching inhibition in garden pea: Molecule design for shoot branching. Plant Physiol 159: 1524-1544. doi:10.1104/pp.112.195826

Brewer PB, Yoneyama K, Filardo F, Meyers E, Scaffidi A, Frickey T, Akiyama K, Seto Y, Dun EA, Cremer JE, et al. 2016. LATERAL BRANCHING OXIDOREDUCTASE acts in the final stages of strigolactone biosynthesis in Arabidopsis. Proc Natl Acad Sci 113: 6301-6306. doi:10 $.1073 /$ pnas. 1601729113

Butler LG. 1995. Chemical communication between the parasitic weed Striga and its crop host. A new dimension in allelochemistry. In Allelopathy, organisms, processes and applications (ed. Inderjit KM, Dakshini M, Enhelling FA), pp. 158-168. American Chemical Society, Washington, DC.

Charnikhova TV, Gaus K, Lumbroso A, Sanders M, Vincken JP, De Mesmaeker A, Ruyter-Spira CP, Screpanti C, Bouwmeester HJ. 2017. Zealactones. Novel natural strigolactones from maize. Phytochemistry 137: 123-131. doi:10.1016/j.phytochem.2017.02.010

Conn CE, Bythell-Douglas R, Neumann D, Yoshida S, Whittington B, Westwood JH, Shirasu K, Bond CS, Dyer KA, Nelson DC. 2015. Convergent evolution of strigolactone perception enabled host detection in parasitic plants. Science 349: 540-543. doi:10.1126/science.aab1140

Cook CE, Whichard LP, Turner B, Wall ME, Egley GH. 1966. Germination of witchweed (Striga lutea Lour.): Isolation and properties of a potent stimulant. Science 154: 11891190. doi:10.1126/science.154.3753.1189
Decker EL, Alder A, Hunn S, Ferguson J, Lehtonen MT, Scheler B, Kerres KL, Wiedemann G, Safavi-Rizi V, Nordzieke S, et al. 2017. Strigolactone biosynthesis is evolutionarily conserved, regulated by phosphate starvation and contributes to resistance against phytopathogenic fungi in a moss, Physcomitrella patens. New Phytol 216: 455-468. doi:10.1111/nph.14506

De Cuyper C, Fromentin J, Yocgo RE, De Keyser A, Guillotin B, Kunert K, Boyer FD, Goormachtig S. 2015. From lateral root density to nodule number, the strigolactone analogue GR24 shapes the root architecture of Medicago truncatula. J Exp Bot 66: 137-146. doi:10.1093/jxb/ eru404

de Saint Germain A, Ligerot Y, Dun EA, Pillot JP, Ross JJ, Beveridge CA, Rameau C. 2013. Strigolactones stimulate internode elongation independently of gibberellins. Plant Physiol 163: 1012-1025.

de Saint Germain A, Clavé G, Badet-Denisot MA, Pillot JP, Cornu D, Le Caer JP, Burger M, Pelissier F, Retailleau P, Turnbull C, et al. 2016. An histidine covalent receptor and butenolide complex mediates strigolactone perception. Nat Chem Biol 12: 787-794. doi:10.1038/nchembio.2147

Dun EA, Brewer PB, Beveridge CA. 2009. Strigolactones: Discovery of the elusive shoot branching hormone. Trends Plant Sci 14: 364-372. doi:10.1016/j.tplants.2009 .04 .003

Ejeta G, Gressel J. 2007. Integrating new technologies for striga control: Towards ending the witch-hunt. World Scientific, Singapore.

Ferguson BJ, Mens C, Hastwell AH, Zhang M, Su H, Jones $\mathrm{CH}, \mathrm{Chu}$ X, Gresshoff PM. 2019. Legume nodulation: The host controls the party. Plant Cell Environ 42: 41-51. doi:10.1111/pce.13348

Flematti GR, Ghisalberti EL, Dixon KW, Trengove RD. 2004. A compound from smoke that promotes seed germination. Science 305: 977. doi:10.1126/science.1099944

Foo E, Davies NW. 2011. Strigolactones promote nodulation in pea. Planta 234: 1073-1081. doi:10.1007/s00425-0111516-7

Foo E, Ross JJ, Jones WT, Reid JB. 2013. Plant hormones in arbuscular mycorrhizal symbioses: An emerging role for gibberellins. Ann Bot 111: 769-779. doi:10.1093/aob/ mct041

Giovannetti M, Sbrana C, Avio L, Citernesi AS, Logi C. 1993. Differential hyphal morphogenesis in arbuscular mycorrhizal fungi during pre-infection stages. New Phytol 125: 587-593. doi:10.1111/j.1469-8137.1993.tb03907.x

Gobena D, Shimels M, Rich PJ, Ruyter-Spira C, Bouwmeester H, Kanuganti S, Mengiste T, Ejeta G. 2017. Mutation in sorghum LOW GERMINATION STIMULANT 1 alters strigolactones and causes Striga resistance. Proc Natl Acad Sci 114: 4471-4476. doi:10.1073/pnas .1618965114

Gomez-Roldan V, Fermas S, Brewer PB, Puech-Pagès V, Dun EA, Pillot JP, Letisse F, Matusova R, Danoun S, Portais JC, et al. 2008. Strigolactone inhibition of shoot branching. Nature 455: 189-194. doi:10.1038/na ture07271

Govindarajulu M, Pfeffer PE, Jin H, Abubaker J, Douds DD, Allen JW, Bücking H, Lammers PJ, Shachar-Hill Y. 2005. Nitrogen transfer in the arbuscular mycorrhizal symbiosis. Nature 435: 819-823. doi:10.1038/nature03610 
Hamiaux C, Drummond Revel SM, Janssen BJ, Ledger SE Cooney JM, Newcomb RD, Snowden KC. 2012. DAD2 is an $\alpha / \beta$ hydrolase likely to be involved in the perception of the plant branching hormone, strigolactone. Curr Biol 22: 2032-2036. doi:10.1016/j.cub.2012.08.007

Jia KP, Baz L, Al-Babili S. 2018. From carotenoids to strigolactones. J Exp Bot 69: 2189-2204. doi:10.1093/jxb/ erx476

Joel DM, Hershenhorn J, Eizenberg H, Aly R, Ejeta G, Rich PJ, Ransom JK, Sauerborn J, Rubiales D. 2007. Biology and management of weedy root parasites In Horticultural reviews (ed. Janick J), pp. 267-349. Wiley, London.

Kapulnik Y, Delaux PM, Resnick N, Mayzlish-Gati E, Wininger S, Bhattacharya C, Séjalon-Delmas N, Combier JP, Bécard G, Belausov E, et al. 2011. Strigolactones affect lateral root formation and root-hair elongation in Arabidopsis. Planta 233: 209-216. doi:10.1007/s00425-0101310-y

Kim HI, Kisugi T, Khetkam P, Xie X, Yoneyama K, Uchida K, Yokota T, Nomura T, McErlean CS, Yoneyama K. 2014. Avenaol, a germination stimulant for root parasitic plants from Avena strigosa. Phytochemistry 103: 85-88. doi:10 .1016/j.phytochem.2014.03.030

Kobae Y, Kameoka H, Sugimura Y, Saito K, Ohtomo R, Fujiwara T, Kyozuka J. 2018. Strigolactone biosynthesis genes of rice are required for the punctual entry of arbuscular mycorrhizal fungi into the roots. Plant Cell Physiol 59: 544-553. doi:10.1093/pcp/pcy001

Kohlen W, Charnikhova T, Liu Q, Bours R, Domagalska MA, Beguerie S, Verstappen F, Leyser O, Bouwmeester H, Ruyter-Spira C. 2011. Strigolactones are transported through the xylem and play a key role in shoot architectural response to phosphate deficiency in nonarbuscular mycorrhizal host Arabidopsis. Plant Physiol 155: 974987. doi:10.1104/pp.110.164640

Koltai H. 2011. Strigolactones are regulators of root development. New Phytol 190: 545-549. doi:10.1111/j.14698137.2011.03678.x

Kouchi H, Imaizumi-Anraku H, Hayashi M, Nakagawa T, Umehara Y, Kouchi H, Hakoyama T, Suganuma N, Kawaguchi M. 2010. How many peas in a pod? Legume genes responsible for mutualistic symbioses underground. Plant Cell Physiol 51: 1381-1397. doi:10.1093/ pcp/pcq107

Kretzschmar T, Kohlen W, Sasse J, Borghi L, Schlegel M, Bachelier JB, Reinhardt D, Bours R, Bouwmeester HJ, Martinoia E. 2012. A petunia ABC protein controls strigolactone-dependent symbiotic signalling and branching. Nature 483: 341-344. doi:10.1038/nature10873

Lin H, Wang R, Qian Q, Yan M, Meng X, Fu Z, Yan C, Jiang B, Su Z, Li J, et al. 2009. DWARF27, an iron-containing protein required for the biosynthesis of strigolactones, regulates rice tiller bud outgrowth. Plant Cell 21: 15121525. doi:10.1105/tpc.109.065987

Liu W, Kohlen W, Lillo A, Op den Camp R, Ivanov S, Hartog M, Limpens E, Jamil M, Smaczniak C, Kaufmann K, et al. 2011. Strigolactone biosynthesis in Medicago truncatula and rice requires the symbiotic GRAS-type transcription factors NSP1 and NSP2. Plant Cell 23: 3853-3865. doi:10 $.1105 /$ tpc. 111.089771

McAdam EL, Hugill C, Fort S, Samain E, Cottaz S, Davies NW, Reid JB, Foo E. 2017. Determining the site of action of strigolactones during nodulation. Plant Physiol 175: 529-542. doi:10.1104/pp.17.00741

Mohemed NM, Charnikhova T, Bakker EJ, van Ast A, Babiker AG, Bouwmeester HJ. 2016. Evaluation of field resistance to Striga hermonthica (Del.) Benth. in Sorghum bicolor (L.) Moench. The relationship with strigolactones. Pest Manag Sci 72: 2082-2090. doi:10.1002/ps.4426

Mori N, Nishiuma K, Sugiyama T, Hayashi H, Akiyama K. 2016. Carlactone-type strigolactones and their synthetic analogues as inducers of hyphal branching in arbuscular mycorrhizal fungi. Phytochemistry 130: 90-98. doi:10 .1016/j.phytochem.2016.05.012

Nakamura H, Xue YL, Miyakawa T, Hou F, Qin HM, Fukui K, Shi X, Ito E, Ito S, Park SH, et al. 2013. Molecular mechanism of strigolactone perception by DWARF14. Nat Commun 4: 2613. doi:10.1038/ncomms3613

Nelson DC, Scaffidi A, Dun EA, Waters MT, Flematti GR, Dixon KW, Beveridge CA, Ghisalberti EL, Smith SM. 2011. F-box protein MAX2 has dual roles in karrikin and strigolactone signaling in Arabidopsis thaliana. Proc Natl Acad Sci 108: 8897-8902. doi:10.1073/pnas 1100987108

Nickrent DL, Duff RJ, Colwell AE, Wolfe AD, Young ND, Steiner KE, de Pamphilis CW. 1998. Molecular phylogenetic and evolutionary studies of parasitic plants. In $\mathrm{Mo}$ lecular systematics of plants II DNA sequencing (ed. Soltis DE, Solitis PS, Doyle JJ), pp. 211-241. Kluwer, Boston.

Parker C. 2009. Observations on the current status of Orobanche and Striga problems worldwide. Pest Manag Sci 65: 453-459.

Parniske M. 2008. Arbuscular mycorrhiza: The mother of plant root endosymbioses. Nat Rev Microbiol 6: 763-775. doi:10.1038/nrmicro1987

Rasmussen A, Mason MG, De Cuyper C, Brewer PB, Herold S, Agusti J, Geelen D, Greb T, Goormachtig S, Beeckman T, et al. 2012. Strigolactones suppress adventitious rooting in Arabidopsis and pea. Plant Physiol 158: 1976-1987. doi:10.1104/pp.111.187104

Rehman NU, Ali M, Ahmad MZ, Liang G, Zhao J. 2018. Strigolactones promote rhizobia interaction and increase nodulation in soybean (Glycine max). Microb Pathog 114: 420-430. doi:10.1016/j.micpath.2017.11.049

Ruyter-Spira C, Kohlen W, Charnikhova T, van Zeijl A, van Bezouwen L, de Ruijter N, Cardoso C, Lopez-Raez JA, Matusova R, Bours R, et al. 2011. Physiological effects of the synthetic strigolactone analog GR24 on root system architecture in Arabidopsis: another belowground role for strigolactones? Plant Physiol 155: 721-734. doi:10.1104/ pp.110.166645

Scaffidi A, Waters MT, Ghisalbert EL, Dixon KW, Flematti GR, Smith SM. 2013. Carlactone-independent seedling morphogenesis in Arabidopsis. Plant J 76: 1-9.

Seto Y, Sado A, Asami K, Hanada A, Umehara M, Akiyama K, Yamaguchi S. 2014. Carlactone is an endogenous biosynthetic precursor for strigolactones. Proc Natl Acad Sci 111: 1640-1645. doi:10.1073/pnas.1314805111

Seto Y, Yasui R, Kameoka H, Tamiru M, Cao M, Terauchi R, Sakurada A, Hirano R, Kisugi T, Hanada A, et al. 2019. Strigolactone perception and deactivation by a hydrolase receptor DWARF14. Nat Commun 10: 191. doi:10.1038/ s41467-018-08124-7 
Shindo M, Shimomura K, Yamaguchi S, Umehara M. 2018 Upregulation of DWARF27 is associated with increased strigolactone levels under sulfur deficiency in rice. Plant Direct 2: 1-9. doi:10.1002/pld3.50

Siame BA, Weerasuriya Y, Wood K, Ejeta G, Butler LG. 1993. Isolation of strigol, a germination stimulant for Striga asiatica, from host plants. J Agric Food Chem 41: 14861491. doi:10.1021/jf00033a025

Smith SE, Read DJ. 2008. Mycorrhizal symbiosis. Academic Cambridge.

Snowden KC, Simkin AJ, Janssen BJ, Templeton KR, Loucas HM, Simons JL, Karunairetnam S, Gleave AP, Clark DG Klee HJ. 2005. The Decreased apical dominance1/Petunia hybrida CAROTENOID CLEAVAGE DIOXYGENASE8 gene affects branch production and plays a role in leaf senescence, root growth, and flower development. Plant Cell 17: 746-759. doi:10.1105/tpc.104.027714

Soto MJ, Fernández-Aparicio M, Castellanos-Morales V, García-Garrido JM, Ocampo JA, Delgado MJ, Vierheilig H. 2010. First indications for the involvement of strigolactones on nodule formation in alfalfa (Medicago sativa). Soil Biol Biochem 42: 383-385. doi:10.1016/j.soilbio.2009 .11 .007

Stirnberg P, van de Sande K, Leyser HMO. 2002. MAX1 and MAX2 control shoot lateral branching in Arabidopsis. Development 129: 1131-1141.

Takahashi I, Asami T. 2018. Target-based selectivity of strigolactone agonists and antagonists in plants and their potential use in agriculture. J Exp Bot 69: 2241-2254. doi:10.1093/jxb/ery126

Tisserant E, Malbreil M, Kuo A, Kohler A, Symeonidi A, Balestrini R, Charron P, Duensing N, Frei dit Frey N, Gianinazzi-Pearson V, et al. 2013. Genome of an arbuscular mycorrhizal fungus provides insight into the oldest plant symbiosis. Proc Natl Acad Sci 110: 20117-20122. doi:10.1073/pnas.1313452110

Toh S, Holbrook-Smith D, Stogios PJ, Onopriyenko O, Lumba S, Tsuchiya Y, Savchenko A, McCourt P. 2015. Structure-function analysis identifies highly sensitive strigolactone receptors in Striga. Science 350: 203-207. doi:10.1126/science.aac9476

Torres-Vera R, García JM, Pozo MJ, López-Ráez JA. 2014. Do strigolactones contribute to plant defence? Mol Plant Pathol 15: 211-216. doi:10.1111/mpp.12074

Tsuchiya Y. 2018. Small molecule toolbox for strigolactone biology. Plant Cell Physiol 59: 1511-1519. doi:10.1093/ pcp/pcyl19

Tsuchiya Y, Yoshimura M, Sato Y, Kuwata K, Toh S, Holbrook-Smith D, Zhang H, McCourt P, Itami K, Kinoshita T, et al. 2015. Probing strigolactone receptors in Striga hermonthica with fluorescence. Science 349: 864-868. doi:10.1126/science.aab3831

Ueno K, Furumoto T, Umeda S, Mizutani M, Takikawa H, Batchvarova R, Sugimoto Y. 2014. Heliolactone, a nonsesquiterpene lactone germination stimulant for root parasitic weeds from sunflower. Phytochemistry 108: 122128. doi:10.1016/j.phytochem.2014.09.018

Umehara M, Hanada A, Yoshida S, Akiyama K, Arite T, Takeda-Kamiya N, Magome H, Kamiya Y, Shirasu K, Yoneyama K, et al. 2008. Inhibition of shoot branching by new terpenoid plant hormones. Nature 455: 195-200. doi:10.1038/nature07272
Umehara M, Hanada A, Magome H, Takeda-Kamiya N, Yamaguchi S. 2010. Contribution of strigolactones to the inhibition of tiller bud outgrowth under phosphate deficiency in rice. Plant Cell Physiol 51: 1118-1126. doi:10 $.1093 / \mathrm{pcp} / \mathrm{pcq} 084$

Uraguchi D, Kuwata K, Hijikata Y, Yamaguchi R, Imaizumi H AMS, Rakers C, Mori N, Akiyama K, Irie S, et al. 2018. A femtomolar-range suicide germination stimulant for the parasitic plant Striga hermonthica. Science 362: 1301-1305. doi:10.1126/science.aau5445

Vallabhaneni R, Bradbury LMT, Wurtzel ET. 2010. The carotenoid dioxygenase gene family in maize, sorghum, and rice. Arch Biochem Biophys 504: 104-111. doi:10.1016/j .abb.2010.07.019

van Zeijl A, Liu W, Xiao TT, Kohlen W, Yang WC, Bisseling T, Geurts R. 2015. The strigolactone biosynthesis gene DWARF27 is co-opted in rhizobium symbiosis. BMC Plant Biol 15: 260. doi:10.1186/s12870-015-0651-x

Venkateshwaran M, Volkening JD, Sussman MR, Ané JM. 2013. Symbiosis and the social network of higher plants. Curr Opin Plant Biol 16: 118-127. doi:10.1016/j.pbi.2012 .11 .007

Wang Y, Bouwmeester HJ. 2018. Structural diversity in the strigolactones. J Exp Bot 69: 2219-2230. doi:10.1093/jxb/ ery091

Waters MT, Brewer PB, Bussell JD, Smith SM, Beveridge CA. 2012a. The Arabidopsis ortholog of rice DWARF27 acts upstream of MAX1 in the control of plant development by strigolactones. Plant Physiol 159: 1073-1085. doi:10 $.1104 /$ pp.112.196253

Waters MT, Nelson DC, Scaffidi A, Flematti GR, Sun YK, Dixon KW, Smith SM. 2012b. Specialisation within the DWARF14 protein family confers distinct responses to karrikins and strigolactones in Arabidopsis. Development 139: 1285-1295. doi:10.1242/dev.074567

Waters MT, Gutjahr C, Bennett T, Nelson DC. 2017. Strigolactone signaling and evolution. Annu Rev Plant Biol 68: 291-322. doi:10.1146/annurev-arplant-042916-040925

Xie X, Kusumoto D, Takeuchi Y, Yoneyama K, Yamada Y, Yoneyama K. 2007.2'-Epi-orobanchol and solanacol, two unique strigolactones, germination stimulants for root parasitic weeds, produced by tobacco. J Agric Food Chem 55: 8067-8072. doi:10.1021/jf0715121

Xie X, Yoneyama K, Harada Y, Fusegi N, Yamada Y, Ito S, Yokota T, Takeuchi Y, Yoneyama K. 2009. Fabacyl acetate, a germination stimulant for root parasitic plants from Pisum sativum. Phytochemistry 70: 211-215. doi:10 .1016/j.phytochem.2008.12.013

Xie X, Yoneyama K, Yoneyama K. 2010. The strigolactone story. Annu Rev Phytopathol 48: 93-117. doi:10.1146/an nurev-phyto-073009-114453

Xie X, Yoneyama K, Kisugi T, Uchida K, Ito S, Akiyama K, Hayashi H, Yokota T, Nomura T, Yoneyama K. 2013. Confirming stereochemical structures of strigolactones produced by rice and tobacco. Mol Plant 6: 153-163. doi:10.1093/mp/sss 139

Xie X, Kisugi T, Yoneyama K, Nomura T, Akiyama K, Uchida K, Yokota T, McErlean CSP, Yoneyama K. 2017. Methyl zealactonoate, a novel germination stimulant for root parasitic weeds produced by maize. J Pestic Sci 42: 58-61. doi:10.1584/jpestics.D16-103 
K. Yoneyama

Yamada Y, Furusawa S, Nagasaka S, Shimomura K, Yamaguchi S, Umehara M. 2014. Strigolactone signaling regulates rice leaf senescence in response to a phosphate deficiency. Planta 240: 399-408. doi:10.1007/s00425-0142096-0

Yao R, Ming Z, Yan L, Li S, Wang F, Ma S, Yu C, Yang M, Chen L, Chen L, et al. 2016. DWARF14 is a non-canonical hormone receptor for strigolactone. Nature 536: 469473. doi:10.1038/nature19073

Yokota T, Sakai H, Okuno K, Yoneyama K, Takeuchi Y. 1998. Alectrol and orobanchol, germination stimulants for Orobanche minor, from its host red clover. Phytochemistry 49: 1967-1973. doi:10.1016/S0031-9422(98)00419-1

Yoneyama K, Takeuchi Y, Yokota T. 2001. Production of clover broomrape seed germination stimulants by red clover root requires nitrate but is inhibited by phosphate and ammonium. Physiol Plant 211: 25-30. doi:10.1034/j .1399-3054.2001.1120104.x

Yoneyama K, Xie X, Kusumoto D, Sekimoto H, Sugimoto Y, Takeuchi Y, Yoneyama K. 2007a. Nitrogen deficiency as well as phosphorus deficiency in sorghum promotes the production and exudation of 5-deoxystrigol, the host recognition signal for arbuscular mycorrhizal fungi and root parasites. Planta 227: 125-132. doi:10.1007/s00425-0070600-5

Yoneyama K, Yoneyama K, Takeuchi Y, Sekimoto H. 2007b. Phosphorus deficiency in red clover promotes exudation of orobanchol, the signal for mycorrhizal symbionts and germination stimulant for root parasites. Planta 225: 1031-1038. doi:10.1007/s00425-006-0410-1

Yoneyama K, Xie X, Sekimoto H, Takeuchi Y, Ogasawara S, Akiyama K, Hayashi H, Yoneyama K. 2008. Strigolactones, host recognition signals for root parasitic plants and arbuscular mycorrhizal fungi, from Fabaceae plants. New Phytol 179: 484-494. doi:10.1111/j.1469-8137.2008 .02462. $\mathrm{x}$

Yoneyama K, Xie X, Kisugi T, Nomura T, Sekimoto H, Yokota T, Yoneyama K. 2011. Characterization of strigolactones exuded by Asteraceae plants. Plant Growth Regul 65: 495-504. doi:10.1007/s10725-011-9620-Z
Yoneyama K, Xie X, Kim HI, Kisugi T, Nomura T, Sekimoto H, Yokota T, Yoneyama K. 2012. How do nitrogen and phosphorus deficiencies affect strigolactone production and exudation? Planta 235: 1197-1207. doi:10.1007/ s00425-011-1568-8

Yoneyama K, Arakawa R, Ishimoto K, Kim HI, Kisugi T, Xie X, Nomura T, Kanampiu F, Yokota T, Ezawa T, et al. 2015 Difference in Striga-susceptibility is reflected in strigolactone secretion profile, but not in compatibility and host preference in arbuscular mycorrhizal symbiosis in two maize cultivars. New Phytol 206: 983-989. doi:10.1111/ nph.13375

Yoneyama K, Mori N, Sato T, Yoda A, Xie X, Okamoto M, Iwanaga $\mathrm{M}$, Ohnishi $\mathrm{T}$, Nishiwaki $\mathrm{H}$, Asami T, et al. 2018a. Conversion of carlactone to carlactonoic acid is a conserved function of MAX1 homologs in strigolactone biosynthesis. New Phytol 218: 1522-1533. doi:10.1111/ nph. 15055

Yoneyama K, Xie X, Yoneyama K, Kisugi T, Nomura T, Nakatani Y, Akiyama K, McErlean CSP. 2018b. Which are the major players, canonical or non-canonical strigolactones? J Exp Bot 69: 2231-2239. doi:10.1093/jxb/ ery090

Yoneyama K, Xie X, Yoneyama K, Nomura T, Takahashi I, Asami T, Mori N, Akiyama K, Kusajima M, Nakashita H. 2019. Regulation of biosynthesis, perception, and functions of strigolactones for promoting arbuscular mycorrhizal symbiosis and managing root parasitic weeds. Pest Manag Sci (in press).

Yoshida S, Kameoka H, Tempo M, Akiyama K, Umehara M, Yamaguchi S, Hayashi H, Kyozuka J, Shirasu K. 2012. The D3 F-box protein is a key component in host strigolactone responses essential for arbuscular mycorrhizal symbiosis. New Phytol 196: 1208-1216. doi:10.1111/j.1469-8137 .2012.04339.x

Zhang Y, van Dijk ADJ, Scaffidi A, Flematti GR, Hofmann M, Charnikhova T, Verstappen F, Hepworth J, van der Krol S, Leyser O, et al. 2014. Rice cytochrome P450 MAX1 homologs catalyze distinct steps in strigolactone biosynthesis. Nat Chem Biol 10: 1028-1033. doi:10.1038/nchem bio. 1660 


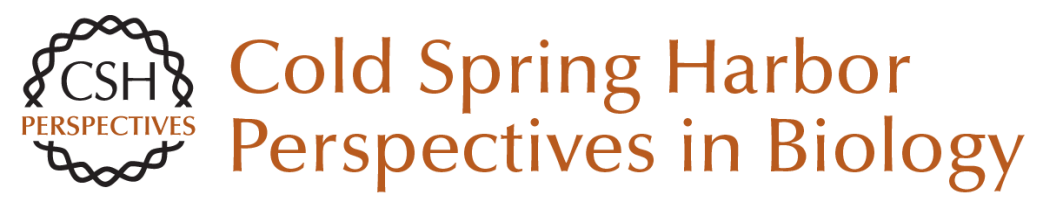

\section{How Do Strigolactones Ameliorate Nutrient Deficiencies in Plants?}

Kaori Yoneyama

Cold Spring Harb Perspect Biol 2019; doi: 10.1101/cshperspect.a034686 originally published online May 14, 2019

\section{Subject Collection Engineering Plants for Agriculture}

Plant Inflorescence Architecture: The Formation, Activity, and Fate of Axillary Meristems Yang Zhu and Doris Wagner

Sub1 Rice: Engineering Rice for Climate Change Kyle Emerick and Pamela C. Ronald

Engineering Disease-Resistant Cassava Z.J. Daniel Lin, Nigel J. Taylor and Rebecca Bart

Many Facets of Dynamic Plasticity in Plants Xiaodong Yang and Sally A. Mackenzie

How Do Strigolactones Ameliorate Nutrient Deficiencies in Plants?

Kaori Yoneyama

Mechanisms and Impact of Symbiotic Phosphate Acquisition Chai Hao Chiu and Uta Paszkowski
The Sweet Side of Plant-Specialized Metabolism Thomas Louveau and Anne Osbourn

The Role of Dwarfing Traits in Historical and Modern Agriculture with a Focus on Rice Ángel Ferrero-Serrano, Christian Cantos and Sarah M. Assmann

Bt Brinjal in Bangladesh: The First Genetically Engineered Food Crop in a Developing Country Anthony M. Shelton, Md. J. Hossain, Vijay Paranjape, et al.

Circadian Rhythms in Plants Nicky Creux and Stacey Harmer

Developing Blight-Tolerant American Chestnut Trees William A. Powell, Andrew E. Newhouse and Vernon Coffey

Stomatal Development and Perspectives toward Agricultural Improvement Hitoshi Endo and Keiko U. Torii

For additional articles in this collection, see http://cshperspectives.cshlp.org/cgi/collection/

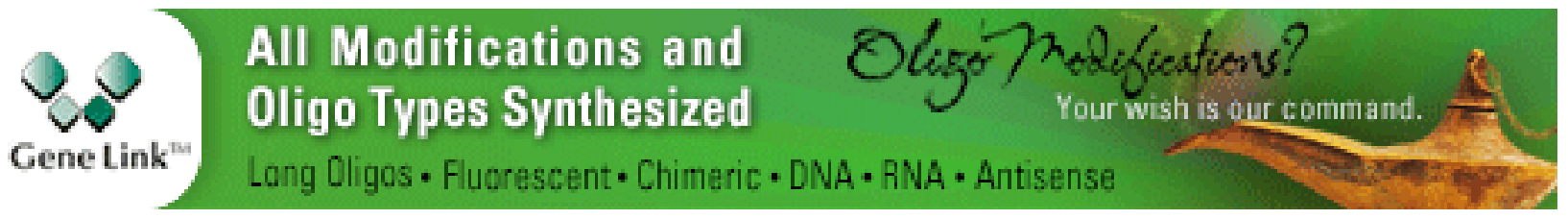

